\title{
Prevalence of psychological distress and associated factors among orthopedic trauma patients at Tikur Anbessa specialized hospital, Addis Ababa, Ethiopia: A cross- sectional study
}

\author{
Mengesha Srahbzu Biresaw ${ }^{*}$, Tolesa Fanta Jilcha ${ }^{2}$ and Enguday Tirfeneh Gebeyehu ${ }^{3}$ \\ ${ }^{1} \mathrm{MSC}$ in Integrated Clinical and Community Mental Health, Department of psychiatry, University of Gondar, college of medicine and health science, Gondar, Ethiopia \\ ${ }^{2} \mathrm{MSC}$ in Integrated Clinical and Community Mental Health, Department of research, Amanuel mental specialized hospital, Addis Ababa, Ethiopia \\ ${ }^{3} \mathrm{MSC}$ in Integrated Clinical and Community Mental Health, Department of psychiatry, Aksum University, college of medicine and health science, Aksum, Ethiopia
}

\begin{abstract}
Background: Orthopedic Trauma exerts a holistic influence on survivors' physical health including a range of mental health problems that interfere with survivors' recovery. Psychiatric disorders and behavioral disturbances are reported to be 3-5 times more common among people with injuries and are a predictor of poor outcome and ongoing disability. Assessing psychological distress among orthopedic trauma patients plays a pivotal role to implement further intervention.

Methods: Institutional based cross-sectional study was conducted at Tikur Anbessa specialized hospital. Hospital anxiety and depression scale was used to assess psychological distress by using face to face interview. A systematic sampling technique was used to select a total of 407participants. Data has been analyzed using SPSS 20. Bivariate and multivariate logistic regression was done to identify associated factors. Variables with p-value $<0.05$ have been considered as statistically significant.

Result: prevalence of psychological distress was 35.4\%. independent variables like being female (adjusted odd ratio (AOR)=1.65 95\% confidence interval (CI) $(1.89,3.04))$, poor social support (AOR=3.51 95\%CI $(1.39,8.88)$ ), moderate social support (AOR=2.75 95\%CI (1.13,6.72)), having chronic medical illness (AOR=2.24 95\%CI $(1.16,4.32))$, presence of amputation (AOR=2.90 95\%CI $(1.97,8.73)$ ) and having severe pain $(\mathrm{AOR}=2.5095 \% \mathrm{CI}(1.20,5.18))$ found to have significant association at $\mathrm{p}$-value $<0.05$ with psychological distress.
\end{abstract}

Conclusion and recommendation; the prevalence of psychological distress was high. Being female, having poor social support, having a chronic medical illness, the presence of amputation and having severe pain were significantly associated factors with psychological distress. It is good if clinicians give emphasis to orthopedic patients especially for females and with chronic medical illnesses.

Abbreviations: AOR: Adjusted Odd Ratio, CI: Confidence Interval, HADS: Hospital Anxiety and Depression Scale, NPRS: Numeric Pain Rating Scale: BDI: Beck Depression Inventory

\section{Background}

Injuries to the musculoskeletal system constitute $16 \%$ of the total burden of disease worldwide [1], this makes it the leading cause of morbidity. Most orthopedic traumas may lead to death even though some of them survive with different unpleasant health outcomes [2]. One world health organization data indicates that 20-50 million people have experienced non-fatal musculoskeletal injuries annually throughout the world [3].

The burden of orthopedic trauma is enormous on survivors, their families and the society at large. It greatly affects the survivors' mental health which interferes with their recovery [4]. Survivors may develop psychological distresses soon with months and years after experiencing the trauma [5]. Globally, the mental health problem in orthopedic trauma survivors is reported to be as common as three to five times than the general population [6].

Even though a significant number of orthopedic trauma survivors develop serious psychiatric disorders, only a few of them are praised to get the appropriate mental health service by trained professionals [7]. Millions of traumatic injury victims suffer from physical disabilities which may last longer during their year of work-life [8].

Different emotional and behavioral conditions in sufferers following experiencing musculoskeletal system is a common source of patient complaints $[9,10]$. The magnitude of psychological distresses after sustaining orthopedic trauma varies depending on the screening tool, site of injury and the duration of the study period to the injury. A study conducted in India found that 1 in $5(22 \%)$ patients met the criteria for psychological illness. Mental health problems has been reported to have an association with reduced health-related quality of life $[11,12]$.

${ }^{\star}$ Correspondence to: Mengesha Srahbzu Biresaw, MSC in Integrated Clinical and Community Mental Health, Department of psychiatry, University of Gondar, college of medicine and health science, Gondar, Ethiopia, E-mail: mengusew@gmail.com

Key words: psychological distress, orthopedic trauma, Hospital anxiety, and depression scale

Received: November 01, 2019; Accepted: November 13, 2019; Published: November 18, 2019 
In another study that was conducted after sufferers experienced severe orthopedic trauma, psychological distress has been found in $14 \%$ of them [13]. Psychological distress has been also studied among male orthopedic trauma survivors. According to the result, $30 \%$ satisfied the criteria for psychological distress [14].

A 24-month follow-up study among severe orthopedic trauma survivors reported a $42 \%$ prevalence of psychological disorder. Among this, only $22 \%$ of such patients reported receiving mental health services [10]. In a study conducted at the Philippines among medically ill patients prevalence of psychological distress in the orthopedic unit was found to be $43.9 \%$ [15].

Little attention has been given to the negative mental health outcomes of orthopedic trauma in Ethiopia which is against its burden. This might be due to the reason that there are limited researches in this area showing its burden. Therefore, this study described the prevalence of psychological distress and associated factors among the orthopedic population in the study area. The results of this study will serve as a source of direction for intervention by being input in planning future services for survivors of orthopedic trauma.

\section{Methods}

\section{Study setting and population}

Institutional based cross-sectional study was conducted at Tikur Anbessa specialized hospital. The study population includes orthopedic trauma patients visiting Tikur Anbessa specialized hospital during the data collection period. Those orthopedic trauma patients who are on follow up and aged 16-65 were tried to be included in the study and those orthopedic trauma patients who were severely sick and unable to communicate were excluded from the study.

\section{Sample size determination}

The sample size was calculated by using a single population proportion formula, Considering the following assumptions; prevalence $\mathbf{p}=50 \%$ because no similar study done in our country among orthopedic population, 95\% confidence interval, margin of error $5 \%$, a nonresponse rate $10 \%$. Therefore the final sample size was 423. A systematic sampling technique was applied to select study units at the orthopedic outpatient clinic during the study period. Sampling interval $(\mathrm{k})$ was determined by dividing the total study population during the one-month data collection period by a total sample size then the starting point was randomly selected.

\section{Data collection}

A structured interviewer-administered questionnaire was used which has five subsections: a socio-demographic questionnaire to assess the patients' background information. Hospital anxiety and depression scale (HADS) were applied to determine psychological distress [16]. The reliability of HADS found to have Cronbach's $a$ of 0.78. A cutoff point of $\geq 16$ is considered for participants to be positive for psychological distress [17]. Substance use history was assessed by yes/no answers of respondents and is operationalized according to different literatures. Similarly, chronic medical illness and family mental illness were assessed by yes/no answers of respondents. Social support was measured by the Oslo-3 social support scale. It has the sum score ranging from 3-14 [18]. The numeric pain rating scale (NPRS) was used to measure the intensity of pain. The scoring ranges from 0-10 and classified into four scales as no pain, mild pain, moderate and severe pain [19].

\section{Data processing, analysis, interpretation, and presentation}

The completed data was entered using Epi-info 7 then it was exported to SPSS 20 version statistical software for analysis. Descriptive statistics, bivariate analysis, and multivariate logistic regression were used. The significance was declared at p-value $<0.05$. The strength of association was described using the adjusted odds ratio (AOR) with its respective $95 \%$ CI. Results are presented in the form of tables and graphs using frequency and summary statistics such as mean and percentage to describe the study population in relation to relative variables and discussed with previous results.

\section{Results}

\section{Socio-demographic characteristics}

A total of 407 participants with a response rate of $96.21 \%$ were included in the study. Among this 260 (63.9\%) were males. The mean age of the participants was 37 years with standard deviation of $(\mathrm{SD}= \pm$ $13.5 \mathrm{yrs})$ ranges from 16 to 65 years, more than one fourth 109 (26.8\%) were in age group of 26-35 years, 266 (65.4\%) were orthodox Christian religion followers, 227 (55.8\%) were married, 257 (63.1\%) reported as they have children which range from 1 to11, $162(39.8 \%)$ were Amhara by ethnicity followed by Oromo accounted for 133 (32.7\%) of participant (Table 1).

\section{Clinical and substance-related factors of participants}

According to clinical factors, 99 (24.3\%) of them have reported as they had comorbid medical illness among this half 49 (49.5\%) of the participants were hypertension patients followed by diabetes mellitus patients which were $34(34.3 \%)$ and $18(18.2 \%)$ of them had other cardiac problems.

Regarding current and lifetime substance use, 99 (24.3\%) of them used khat in their lifetime and $25(6.1 \%)$ of them used khat within the last 3 months, more than half $222(54.5 \%)$ of the respondents were lifetime alcohol users, and 69 (17.0\%) were current alcohol users.43 $(10.6 \%)$ of participants used tobacco products in their lifetime and 10 (2.5\%) were current tobacco product users.

\section{Psychosocial and trauma-related factors of participants}

From the total participants, 167 (41.0\%) had poor social support among this 68 of them were females, $164(40.3 \%)$ had moderate social support and among this 62 of them were females and $76(18.7 \%)$ had good social support in which females accounted for almost half 34 . According to trauma-related factors of respondents, 133 (32.7\%) had upper extremity injury, 294 (72.2\%) had lower extremity injury and 16 (3.9\%) had injuries from both upper and lower extremity. Road traffic accident was the cause for injury in 174 (42.8\%) of study participants followed by a falling accident which was responsible for orthopedic injury in $110(27.0 \%)$ of participants.

Regarding the type of injury, 290 (71.3\%) were fractured among these closed fractures accounted for almost half 143 (49.3\%). 67 (16.5\%) developed complication and among these 60 (89.6\%) developed an infection. A total of $36(8.8 \%)$ have undergone amputation, in which $13(34.2 \%)$ have undergone amputation in their upper extremity and 25 (65.8\%) have undergone amputation in their lower extremity. Pain was reported by 257 (63.1\%) of study participants. The mean pain intensity score was $4.51(\mathrm{SD}=2.34)$ which ranges from1-10, among those 110 (27.0\%) had mild pain, 83 (20.4\%) of them has moderate pain and 64 (15.7\%) had severe pain within the past 12 hours (Table 2). 
Biresaw MS (2019) Prevalence of psychological distress and associated factors among orthopedic trauma patients at Tikur Anbessa specialized hospital, Addis Ababa, Ethiopia: A cross-sectional study

\section{Prevalence of psychological distress}

My study showed that the prevalence of psychological distress was $144(35.4 \%)$ with $95 \%$ CI $(30.5,40.0)$. The prevalence rate was higher among females since $77 / 164(47.0 \%)$ is higher when compared to $67 / 243(27.6 \%)$ of males met the screening criteria for psychological distress in the study.

\section{Factors associated with psychological distress}

Bivariate analysis of factors for depression revealed that independent variables; sex, marital status, educational status, monthly income, social support, chronic medical illness, pain severity, having family history of mental illness, having lower extremity injury, developing complication and presence of amputation were found to be candidate variables for multivariate analysis at $\mathrm{p}$-value $<0.2$.

Table 1. Distribution of orthopedic trauma patients visiting orthopedic unit of Tikur Anbessa specialized hospital, Addis Ababa, Ethiopia $(\mathrm{n}=407)$

\begin{tabular}{|c|c|c|c|}
\hline Variable & & frequency & Percent (\%) \\
\hline \multirow{2}{*}{ Sex } & Male & 243 & 59.7 \\
\hline & Female & 164 & 40.3 \\
\hline \multirow{5}{*}{ Age } & $16-25$ & 103 & 25.3 \\
\hline & $26-35$ & 109 & 26.8 \\
\hline & $36-45$ & 82 & 20.1 \\
\hline & $46-55$ & 69 & 17.0 \\
\hline & $56-65$ & 44 & 10.8 \\
\hline \multirow{4}{*}{ Religion } & Orthodox & 266 & 65.4 \\
\hline & Muslim & 72 & 17.7 \\
\hline & Protestant & 55 & 13.5 \\
\hline & Other" & 14 & 3.4 \\
\hline \multirow{4}{*}{ Marital status } & Married & 227 & 55.8 \\
\hline & Single & 121 & 29.7 \\
\hline & Divorced & 31 & 7.6 \\
\hline & widowed/widower & 28 & 6.9 \\
\hline \multirow{2}{*}{ have children } & Yes & 257 & 63.1 \\
\hline & No & 150 & 36.9 \\
\hline \multirow{2}{*}{ No of children } & 1-3 children & 159 & 61.9 \\
\hline & $>=4$ children & 98 & 38.1 \\
\hline \multirow{6}{*}{ Ethnicity } & Amhara & 162 & 39.8 \\
\hline & Oromo & 133 & 32.7 \\
\hline & Tigre & 46 & 11.3 \\
\hline & Gurage & 41 & 10.1 \\
\hline & Welayita & 14 & 3.4 \\
\hline & Other** & 11 & 2.7 \\
\hline \multirow{2}{*}{ Residence } & Rural & 82 & 20.1 \\
\hline & Urban & 325 & 79.9 \\
\hline \multirow{5}{*}{ Educational level } & Can't read \& write & 53 & 13.0 \\
\hline & elementary school & 111 & 27.3 \\
\hline & high school & 109 & 26.8 \\
\hline & preparatory school & 39 & 9.6 \\
\hline & college and above & 95 & 23.3 \\
\hline \multirow{2}{*}{ Job } & Employed & 122 & 30 \\
\hline & Employed & 285 & 70 \\
\hline \multirow{2}{*}{ Monthly income } & $\begin{array}{l}\text { Below poverty bench } \\
\text { mark }\end{array}$ & 189 & 46.4 \\
\hline & $\begin{array}{l}\text { Above poverty bench } \\
\text { mark }\end{array}$ & 218 & 53.6 \\
\hline
\end{tabular}

$*=$ Catholic, Adventist **=Kefa, Siltie, Sidamo
Table 2. Description of trauma-related factors among orthopedic trauma patients visiting the orthopedic unit of Tikur Anbessa specialized hospitals, Addis Ababa, Ethiopia ( $\mathrm{n}=407)$

\begin{tabular}{|c|c|c|c|}
\hline \multicolumn{2}{|l|}{ Variables } & \multirow{2}{*}{$\begin{array}{c}\text { Frequency }(\mathbf{N}) \\
133\end{array}$} & \multirow{2}{*}{$\begin{array}{c}\text { Percent (\%) } \\
32.7\end{array}$} \\
\hline Upper extremity & Yes & & \\
\hline injury & No & 274 & 67.3 \\
\hline \multirow{2}{*}{ lower extremity } & Yes & 294 & 72.2 \\
\hline & No & 113 & 27.8 \\
\hline \multirow{2}{*}{$\begin{array}{l}\text { Multiple limb } \\
\text { injury }\end{array}$} & Yes & 16 & 3.9 \\
\hline & No & 391 & 96.1 \\
\hline \multirow{7}{*}{ Cause for injury } & Road traffic accident & 174 & 42.8 \\
\hline & Fall & 110 & 27.0 \\
\hline & Assault/blow & 55 & 13.5 \\
\hline & Machine & 5 & 1.2 \\
\hline & Crash & 30 & 7.4 \\
\hline & Bullet/blast & 16 & 3.9 \\
\hline & Other* & 17 & 4.2 \\
\hline \multirow{4}{*}{ Type of injury } & $\begin{array}{l}\text { Fracture (yes) } \\
\text { Closed } \\
\text { Open } \\
\text { Fracture \& dislocation }\end{array}$ & $\begin{array}{c}290 \\
143 \\
92 \\
57\end{array}$ & $\begin{array}{l}71.3 \\
49.3 \\
31.0 \\
19.7\end{array}$ \\
\hline & Dislocation and sprain (yes) & 47 & 11.5 \\
\hline & Ligament injury & 37 & 9.1 \\
\hline & Other** & 40 & 9.8 \\
\hline \multirow{2}{*}{ Complication } & Yes & 67 & 16.5 \\
\hline & No & 340 & 83.5 \\
\hline \multirow{3}{*}{$\begin{array}{l}\text { Type of } \\
\text { complication }\end{array}$} & infection & 60 & 89.6 \\
\hline & gangrene & 5 & 7.4 \\
\hline & Other*** & 2 & 3.0 \\
\hline \multirow{3}{*}{$\begin{array}{l}\text { Duration since } \\
\text { injured }\end{array}$} & $<=3$ month & 141 & 34.6 \\
\hline & 4-6 month & 97 & 23.8 \\
\hline & $>6$ month & 169 & 41.5 \\
\hline \multirow{2}{*}{ Pain } & Yes & 257 & 63.1 \\
\hline & No & 150 & 36.9 \\
\hline \multirow{3}{*}{ Pain intensity } & mild & 110 & 42.8 \\
\hline & moderate & 83 & 32.3 \\
\hline & severe & 64 & 24.9 \\
\hline
\end{tabular}

$*=$ medical illness (DM, cancer, muscle TB), chill, unknown cause

$* *=$ nerve injury, medical amputation $* * *=$ sepsis, fibrosis

These factors were entered into multivariate logistic regression for further analysis in order to control confounding effects. As a result being female, poor social support, presence of amputation and having severe pain are found to be statistically significant with psychological distress at the $\mathrm{p}$-value of less than 0.05 . Females were 1.65 times more likely to develop psychological distress than males (AOR $=1.65,95 \%$ CI:1.89,3.04), those who had poor social support were 3.51 times more likely to develop psychological distress as compared to those who had good social support ( $\mathrm{AOR}=3.51,95 \% \mathrm{CI}: 1.39,8.88$ ), the odds of developing psychological distress among those with moderate social support 2.75 times higher as compared to those with strong social support (AOR $=2.75,95 \%$ CI: 1.13, 6.72), the odds of developing psychological distress among those who undergo amputation were 2.90 times higher as compared to those who didn't undergo amputation (AOR $=2.90,95 \%$ CI: $1.97,8.73$ ), those who had chronic medical illness were 2.24 times more likely to develop psychological distress as compared to those who didn't have chronic medical illness (AOR $=2.24,95 \% \mathrm{CI}: 1.16,4.32)$ and Participants who had severe pain within 24 hours were 2.50 times more likely to develop depression than participants who didn't have pain $(\mathrm{AOR}=2.50,95 \% \mathrm{CI}: 1.20,5.18)$ (Table 3$)$. 
Biresaw MS (2019) Prevalence of psychological distress and associated factors among orthopedic trauma patients at Tikur Anbessa specialized hospital, Addis Ababa, Ethiopia: A cross-sectional study

Table 3. Bivariate and multivariable analysis of factors associated with psychological distress among orthopedic trauma patients visiting the orthopedic unit of Tikur Anbessa specialized hospitals, Addis Ababa, Ethiopia $(\mathrm{n}=407)$

\begin{tabular}{|c|c|c|c|c|c|}
\hline \multirow{2}{*}{\multicolumn{2}{|c|}{ Variables }} & \multicolumn{2}{|c|}{ Psychological distress } & \multirow{3}{*}{$\begin{array}{c}\text { COR }(\mathbf{9 5} \% \mathrm{CI}) \\
1\end{array}$} & \multirow{3}{*}{$\begin{array}{c}\text { AOR (95 CI \%) } \\
1\end{array}$} \\
\hline & & \multirow{2}{*}{$\begin{array}{c}\text { YES } \\
67\end{array}$} & \multirow{2}{*}{$\begin{array}{l}\text { No } \\
176\end{array}$} & & \\
\hline Sex & Male & & & & \\
\hline Sex & Female & 77 & 87 & $2.33(1.53,3.53)$ & $1.65(1.89,3.04)^{*}$ \\
\hline \multirow{3}{*}{ Marital status } & Married & 75 & 152 & 1 & 1 \\
\hline & single & 43 & 78 & $1.12(0.7,1.8)$ & $1.59(.81,3.13)$ \\
\hline & Divorced/widowed & 26 & 33 & $1.60(0.9,2.9)$ & $1.24(.53,2.92)$ \\
\hline \multirow{5}{*}{ Educational status } & Can't read \& write & 23 & 30 & $1.84(0.91,3.69)$ & $1.76(.59,5.22)$ \\
\hline & Elementary & 38 & 73 & $1.25(.69,2.25)$ & $1.35(.57,3.20)$ \\
\hline & high school & 41 & 68 & $1.44(.80,2.60)$ & $1.45(.63,3.32)$ \\
\hline & preparatory school & 14 & 25 & $1.34(.61,2.95)$ & $1.70(.56,5.18)$ \\
\hline & College \& above & 28 & 67 & 1 & 1 \\
\hline \multirow{2}{*}{ Monthly income } & Below poverty bench mark & 73 & 116 & $1.30(.87,1.96)$ & $1.21(.64,2.28)$ \\
\hline & Above poverty bench mark & 71 & 147 & 1 & 1 \\
\hline \multirow{3}{*}{ Social support } & Poor & 70 & 97 & $2.17(1.18,3.96)$ & $3.51(1.39,8.88)^{* *}$ \\
\hline & Moderate & 55 & 109 & $1.51(.82,2.79)$ & $2.75(1.13,6.72)^{*}$ \\
\hline & Good & 19 & 57 & 1 & 1 \\
\hline \multirow{2}{*}{ Chronic medical illness } & Yes & 47 & 52 & $1.97(1.24,3.12)$ & $2.24(1.16,4.32)^{*}$ \\
\hline & No & 97 & 211 & 1 & 1 \\
\hline \multirow{2}{*}{$\begin{array}{l}\text { Family history of mental } \\
\text { illness }\end{array}$} & yes & 28 & 31 & $1.81(1.03,3.16)$ & $1.43(.63,3.24)$ \\
\hline & no & 116 & 232 & 1 & 1 \\
\hline \multirow{2}{*}{ Lower extremity injury } & yes & 112 & 182 & $1.56(.97,2.50)$ & $0.65(0.31,1.37)$ \\
\hline & no & 32 & 81 & 1 & 1 \\
\hline \multirow{2}{*}{ Complication } & yes & 38 & 29 & $2.89(1.69,4.94)$ & $1.98(.96,4.12)$ \\
\hline & no & 106 & 234 & 1 & 1 \\
\hline \multirow{2}{*}{ Amputation } & yes & 23 & 13 & $3.66(1.79,7.46)$ & $2.90(1.97,8.73)^{*}$ \\
\hline & no & 121 & 250 & 1 & 1 \\
\hline \multirow{3}{*}{ pain intensity } & Mild & 34 & 79 & 1 & 1 \\
\hline & Moderate & 55 & 109 & $1.40(.77,2.54)$ & $1.06(.54,2.08)$ \\
\hline & Severe & 19 & 57 & $2.95(1.5,5.6)$ & $2.50(1.20,5.18)^{*}$ \\
\hline
\end{tabular}

$\alpha=0.05$

$*=\mathrm{P}$-value $<0.05$

$* *=\mathrm{P}$-value $<0.0$

$* * *=\mathrm{P}-\mathrm{value}<0.00$

\section{Discussion}

\section{Discussion on the prevalence of psychological distress}

The study revealed that the prevalence of psychological distress was $35.4 \%$. The current study finding for psychological distress was higher than the studies conducted in India 22\% [12] and a study in the USA 19\% [20]. The reason for the above difference might be due to the difference in sample size and study population who were only sportrelated injuries while receiving physical therapy in the USA.

On the contrary finding of this study on the prevalence of psychological distress was lower than a study conducted at USA $42 \%$ [10] and another study in USA 45\% [21] and in the Philippines $43.9 \%$ [15]. This difference might be attributed to measurement tool which was beck depression inventory (BDI) used in US [21], time onset of the study since injury and study participants who were only on patients with severe lower limb injury and study type which was prospective cohort at USA a follow up study and [10] and sample size which was a large scale study among general medical inpatients in Philippines [15].

\section{Discussion on Factors associated with psychological distress}

This study revealed that variables like being female, having poor and moderate social support, those who have chronic medical illness, amputation and having severe pain were found to be statistically significant for depression. Females were 1.65 times more likely to develop psychological distress than males. This study was in line with a study conducted in China $(\mathrm{AOR}=2.62)$ [22]. This study was supported by studies conducted in the US, United Kingdom, Korea, Jordan, Hong Kong Pakistan and India [23-29].

The odds of developing psychological distress among those who have poor social support were 3.51 times higher when compared to those who have strong social support. This may be due to the reason that good social support is known in buffering the negative consequence of traumatic events [30,31]. Our study result has been found to be consistent with other studies in the US and Pakistan [25,32].

Those who had chronic medical illnesses were 2.24 times more likely to develop psychological distress than those who haven't chronic medical illnesses. This may be due to a reduction in functional independence and long term survival time with being a comorbid victim of physical injury and additional systemic illness [33] which appears to undermine the victim's mental wellness and increases patients' susceptibility for mental health problems. This may also be due to immune suppression and neurotransmitter disturbances which are the major causes of morbidity including mental health problems [34,35].

The odds of developing psychological distress among those who undergo amputation were 2.90 times higher as compared to those who didn't undergo amputation. This may be attributed to adjustment reactions to the new event and loss of sense of independence and 
Biresaw MS (2019) Prevalence of psychological distress and associated factors among orthopedic trauma patients at Tikur Anbessa specialized hospital, Addis Ababa, Ethiopia: A cross-sectional study

having to rely on others for some of the most common everyday needs after loss of one or more limbs [36], because victims may come up with difficulties in carrying out daily activities as well as other tasks and it affects their recovery after orthopedic injury. This may result in an increased chance of physical and psychological disabilities which are major causes of emotional distress $[4,36,37]$. This may also be due to the fact that distortion of the patients' body image and decreased selfesteem after amputation which sets a series of emotional, perceptual and psychological reactions [38]. This was supported by a study conducted at Jordan [24].

Those who had severe pain within the last 24 hours were 2.50 times more likely to develop psychological distress than those who didn't have pain within the last 24 hours. This may be due to increased discomfort on patients which leads to increased emotional distress. It may also be due to the fact that pain is shown to cause altered synaptic connectivity at the prefrontal cortex and hippocampus [39], as well as altered dopamine signaling from the ventral tegmental area [40], these changes have been known to trigger negative symptoms of depression [41]. This was supported by studies conducted in the UK and Korea [23,28,29].

\section{Conclusion and recommendation}

Our study found a high prevalence of psychological distress when compared to the general population. Factors like being female, having poor social support, having a chronic medical illness, the presence of amputation and having severe pain were significantly associated with psychological distress. It is good if clinicians working at orthopedic clinics give emphasis on patients' psychological state during evaluating especially for females, those having a comorbid medical illness, those with poor social support, patients who undergo amputation and those with severe pain. It is also good if other researchers conduct a prospective cohort study to investigate the temporal relationship between factors such as comorbid medical illness and amputation, and psychological distress.

\section{Declarations}

\section{Ethical approval and consent to participate}

Ethical clearance was obtained from both the University of Gondar and Amanuel mental specialized hospital Ethical Review committee. Written Informed consent was obtained from participants aged 18 years and above. Written assent was also obtained for those who aged below 18 years from patients' caregivers coming with them. Each respondent was informed about the objective of the study that it will contribute necessary information for policymaker and other concerned bodies. Anyone who was not willing to participate in the study was not forced to participate. They were also informed that all data obtained from them would be kept confidentially by using code instead of any personal identifier and is meant only for the purpose of study. For the participants who were found to be positive for psychological distress during the study, linkage to nearby psychiatric clinic were done in order to have further assessment on their condition and it was done for a total of 18 patients.

\section{Consent for publication}

Not applicable

\section{Availability of data and materials}

The original data set analyzed in this study is not attached to this manuscript for a matter of privacy of study participants. But it is possible to send the data set as per the reviewers' reasonable request by the corresponding author.

\section{Competing interests}

The authors declare that they have no competing interest.

\section{Funding}

This study was supported financially by the University of Gondar and Amanuel mental specialized hospital. These institutions also involved in allowing the study and commenting on the study design and analytical methods.

\section{Authors' contributions}

MS participated in the conception and design of the study, wrote the proposal, participated in data collection, analysis and write up of this manuscript. TF and ET participated in the design of the study, commented on the proposal, analysis and write up and edition of this manuscript. All authors read and approved the final manuscript.

\section{Acknowledgments}

First of all, we would like to express our thanks to the University Of Gondar College Of Medicine and the health science department of psychiatry and Amanuel's mental specialized hospital for giving us the chance to develop this thesis and funding study.

We would like to extend our deepest thankfulness for Tikur Anbessa specialized hospital management staff and orthopedic clinic nurses for their respect and cooperation during the data collection period. We would also like to thank the study participants.

\section{References}

1. Mock C (2004) Guidelines for essential trauma care. World Health Organization.

2. Bhandari M, Busse JW, Hanson BP, Leece P, Ayeni OR, et al. (2008) Psychological distress and quality of life after orthopedic trauma: an observational study. Can $j$ surg 51: 15 .

3. WHO (2009) Dept. of Violence, Injury Prevention, World Health Organization Violence, Injury Prevention, World Health Organization. Global status report on road safety: time for action. World Health Organization.

4. Woolf AD, Pfleger B (2003) Burden of major musculoskeletal conditions. Bull World Health Organ 81: 646-656.

5. Latchford G (2003) Accident and trauma. The essenfials of clinical health psychology. Wiley, Hoboken, NJ.

6. Kuhn WF, Bell RA, Netscher RE, Seligson D, Kuhn SJ (1990) Psychiatric assessment of leg fracture patients: A pilot study. Int J Psychiatry Med 19: 145-154.

7. Wong EC, Kennedy D, Marshall GN, Gaillot S (2011) Making sense of posttraumatic stress disorder: Illness perceptions among traumatic injury survivors. Psychol Trauma 3: 67 .

8. Steel JL, Dunlavy AC, Stillman J, Pape HC (2011) Measuring depression and PTSD after trauma: Common scales and checklists. Injury 42: 288-300.

9. Chaitanya A, Kumar P (2015) Pschological distress following orthopaedic Trauma-A review. JAMDSR 3: 63

10. McCarthy ML, MacKenzie EJ, Edwin D, Bosse MJ, Castillo RC, et al. (2003) Psychological distress associated with severe lower-limb injury. JBJS 85: 1689-1697.

11. Hutson Jr JJ (2004) Outcomes after treatment of high-energy tibial plafond fractures. $J$ Bone Joint Surg 86: 1827-1828.

12. Remizov VB, Lungu E (2008) Quality of life in patients with orthopedic trauma. $J$ Preventive Med 16: 1-2.

13. O’Donnell ML, Creamer M, Elliott P, Atkin C, Kossmann T (2005) Determinants of quality of life and role-related disability after injury: impact of acute psychological responses. J Trauma Acute Care Surg 59: 1328-1335. 
Biresaw MS (2019) Prevalence of psychological distress and associated factors among orthopedic trauma patients at Tikur Anbessa specialized hospital, Addis Ababa, Ethiopia: A cross-sectional study

14. Mason S, Wardrope J, Turpin G, Rowlands A (2002) The psychological burden of injury: an 18 month prospective cohort study. Emergency Medicine Journal 19: 400-404

15. De Guzman ML (2013) A validation of the Hospital Anxiety and Depression Scale (HADS) in the medically ill. Acta Medica Philippina 47: 53-62.

16. Zigmond AS, Snaith RP (1983) The hospital anxiety and depression scale. Acta Psychiatr Scand 67: 361-370.

17. Reda AA (2011) Reliability and validity of the Ethiopian version of the hospital anxiety and depression scale (HADS) in HIV infected patients. PLoS One 6: e16049.

18. Abiola T, Udofia O, Zakari M (2013) Psychometric properties of the 3-item oslo social support scale among clinical students of Bayero University Kano, Nigeria. MJP 22: $32-41$

19. Mintken PE, Glynn P, Cleland JA (2009) Psychometric properties of the shortened disabilities of the Arm, Shoulder, and Hand Questionnaire (QuickDASH) and Numeric Pain Rating Scale in patients with shoulder pain. J Shoulder Elbow Surg 18: 920-926.

20. Brewer BW, Petitpas AJ, Van Raalte JL, Sklar JH, Ditmar TD (1995) Prevalence of psychological distress among patients at a physical therapy clinic specializing in sports medicine. Res Sports Med 6: 139-145.

21. Crichlow RJ, Andres PL, Morrison SM, Haley SM, Vrahas MS (2007) Depression in orthopaedic trauma patients: prevalence and severity. J Orthop Sports Phys 37: 208.

22. Wu H, Zhang F, Cheng W, Lin Y, Wang Q (2017) Factors related to acute anxiety and depression in inpatients with accidental orthopedic injuries. Shanghai Arch Psychiatry 29: 77.

23. Gong HS, Lee JO, Huh JK, Oh JH, Kim SH, et al. (2011) Comparison of depressive symptoms during the early recovery period in patients with a distal radius fracture treated by volar plating and cast immobilisation. Injury 42: 1266-1270.

24. Hawamdeh ZM, Othman YS, Ibrahim AI (2008) Assessment of anxiety and depression after lower limb amputation in Jordanian patients. Neuropsychiatr Dis Treat 4: 627.

25. Husain N, Humail SM, Chaudhry IB, Rahman R, Robinson H, et al. (2010) Psychological distress among patients of an orthopaedic outpatient clinic: a study from a low-income country. Ann Gen Psychiatry 9: 9.

26. Jain R, Rishi R, Sharma B, Kiyawat V (2015) Role of depression and its associating factors in indoor orthopaedic patients. Asian J Med Sci 6: 70-76.

27. Lam K, Chan SW, Lam SC (2011) Level of psychological distress and social support among patients with limb fractures in Hong Kong. J Clin Nurs 20: 784-793.
28. Podeszwa DA, Richard HM, Nguyen DC, De La Rocha A, Shapiro EL (2015) Preoperative psychological findings in adolescents undergoing hip preservation surgery. J Pediatr Orthop 35: 253-257.

29. Wood RL, Maclean L, Pallister I (2011) Psychological factors contributing to perceptions pain intensity after acute orthopaedic injury. Injury 42: 1214-1218.

30. Cohen S, Wills TA (1985) Stress, social support, and the buffering hypothesis. Psychol Bull 98: 310 .

31. Gariepy G, Honkaniemi H, Quesnel-Vallee A (2016) Social support and protection from depression: systematic review of current findings in Western countries. $\mathrm{Br} J$ Psychiatry 209: 284-293.

32. Barnes RT (2013) Psychological distress in patients with orthopaedic trauma injuries (Doctoral dissertation, University of Florida).

33. Grocott MP, Pearse RM (2010) Prognostic studies of perioperative risk: robust methodology is needed. Br J Anaesth 105: 243.

34. Bufalino C, Hepgul N, Aguglia E, Pariante CM (2013) The role of immune genes in the association between depression and inflammation: a review of recent clinical studies. Brain Behav Immun 31: 31-47.

35. Marik PE, Flemmer M (2012) The immune response to surgery and trauma: Implications for treatment. $J$ Trauma Acute Care Surg 73: 801-808.

36. Bhuvaneswar CG, Epstein LA, Stern TA (2007) Reactions to amputation: recognition and treatment. Prim Care Companion J Clin Psychiatry 9: 303.

37. Crichlow RJ, Andres PL, Morrison SM, Haley SM, Vrahas MS (2006) Depression in orthopaedic trauma patients: prevalence and severity. J Bone Joint Surg Am 88: 1927 1933.

38. Srivastava K, Saldanha D, Chaudhury S, Ryali VS, Goyal S, et al (2010) A study of psychological correlates after amputation. Med J Armed Forces India. 66: 367-373.

39. Geha PY, Baliki MN, Harden RN, Bauer WR, Parrish TB, et al. (2008) The brain in chronic CRPS pain: abnormal gray-white matter interactions in emotional and autonomic regions. Neuron 60: 570-581.

40. Wood PB (2006) Mesolimbic dopaminergic mechanisms and pain control. Pain 120 230-234.

41. Krishnan V, Nestler EJ (2011) Animal models of depression: molecular perspectives In Molecular and functional models in neuropsychiatry, Springer, Berlin, Heidelberg, pp. 121-147.

Copyright: (C2019 Biresaw MS. This is an open-access article distributed under the terms of the Creative Commons Attribution License, which permits unrestricted use, distribution, and reproduction in any medium, provided the original author and source are credited. 